\title{
Impact of extreme weather conditions on healthcare provision in urban Ghana
}

Samuel N.A. Codjoe ${ }^{1}$, Katherine V. Gough ${ }^{2}$, Robert L. Wilby ${ }^{2}$, Raymond Kasei ${ }^{3}$, Paul W.K. Yankson $^{4}$, Ebenezer F. Amankwaa ${ }^{4}$, Mercy A. Abarike ${ }^{3}$, D. Yaw Atiglo ${ }^{1}$, Sam Kayaga ${ }^{5}$, Peter Mensah ${ }^{4}$, Cuthbert K. Nabilse ${ }^{3}$, and Paula L. Griffiths ${ }^{6}$.

${ }^{1}$ Regional Institute for Population Studies, University of Ghana, P.O. Box LG 96, Legon, Ghana. Email: scodjoe@ug.edu.gh

${ }^{2}$ Department of Geography and Environment, Loughborough University, Loughborough, Leicestershire, UK.

${ }^{3}$ Department of Climate Change and Food Security, University for Development Studies, Tamale, Ghana.

${ }^{4}$ Department of Geography and Resource Development, University of Ghana, Legon.

${ }^{5}$ School of Architecture, Building and Civil Engineering, Loughborough University, Loughborough, Leicestershire, UK.

${ }^{6}$ School of Sports, Exercise and Health Sciences, Loughborough University, Loughborough, Leicestershire, UK. 


\section{Author Contribution}

Samuel N.A. Codjoe: Conceptualisation, Methodology, Data curation, Writing - original draft preparation, Validation, Investigation, Writing - Review and Editing

Katherine V. Gough: Conceptualisation, Methodology, Data curation, Writing - original draft preparation, Validation, Investigation, Writing - Review and Editing, Funding acquisition, Project administration

Robert L. Wilby: Conceptualisation, Methodology, Data curation, Writing - original draft preparation, Validation, Investigation, Writing - Review and Editing, Software

Raymond Kasei: Data curation, Validation, Investigation, Supervision, Software, Project administration

Paul W.K. Yankson: Data curation, Validation, Investigation, Supervision, Project administration

Ebenezer F. Amankwaa: Data curation, Validation, Investigation, Supervision, Project administration

Mercy A. Abarike: Data curation, Validation, Investigation, Supervision

D. Yaw Atiglo: Writing - original draft preparation, Validation, Writing - Review and Editing

Sam Kayaga: Data curation, Validation, Investigation, Supervision

Peter Mensah: Data curation, Validation, Investigation, Supervision

Cuthbert K. Nabilse: Data curation, Validation, Investigation, Supervision, Software

Paula L. Griffiths: Conceptualisation, Methodology, Data curation, Writing - original draft preparation, Validation, Investigation, Writing - Review and Editing 


\section{Impact of extreme weather conditions on healthcare provision in urban Ghana}

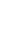

\section{Abstract}

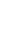

Extreme weather events pose significant threats to urban health in low- and middle-income countries, particularly in sub-Saharan Africa where there are systemic health challenges. This paper investigates health system vulnerabilities associated with flooding and extreme heat, along with strategies for resilience building by service providers and community members, in Accra and Tamale, Ghana. We employed field observations, rainfall records, temperature measurements, and semi-structured interviews in health facilities within selected areas of the cities. Results indicate that poor building conditions, unstable power supply, poor sanitation and hygiene, and the built environment reduce access to healthcare for residents of poor urban areas. Health facilities are sited in low-lying areas with poor drainage systems and can be $6^{\circ} \mathrm{C}$ warmer at night than reported by official records from nearby weather stations. This is due to a combination of greater thermal inertia of the buildings and the urban heat island effect. Flooding and extreme heat interact with socioeconomic conditions to impact physical infrastructure and disrupt community health as well as health facility operations. Community members and health facilities make infrastructural and operational adjustments to reduce extreme weather stress and improve healthcare provision to clients. These measures include mobilisation of residents to clear rubbish and unclog drains; elevating equipment to protect it from floods; improving ventilation during extreme heat; and using alternative power sources for emergency surgery and storage during outages. Stakeholders recommend additional actions to manage flood and heat impacts on health in their cities, such as, improving the capacity of drainage systems to carry 
24 floodwaters, and routine temperature monitoring to better manage heat in health facilities.

25 Finally, more timely and targeted information systems and emergency response plans are 26 required to ensure preparedness for extreme weather events in urban areas.

27

28 Keywords: Extreme weather events; urban areas; health care; resilience; health infrastructure; 29 Ghana.

30 


\section{Impact of extreme weather conditions on healthcare provision in urban Ghana}

\section{Highlights}

- Extreme weather events threaten urban health services in sub-Saharan Africa

- Poor citing of urban health facilities exposes them to heat and flood extremes

- Extreme events disrupt existing deficient health infrastructure and care provision

- Effective drainage and temperature management will aid urban healthcare provision

- Early warning and emergency response will help prepare for extreme weather events 
5 Climate change is regarded as the greatest threat to human health this century, with the 6 potential to reverse rapid advances in health over the last 50 years (WHO, 2018). Even under

\section{Impact of extreme weather conditions on healthcare provision in urban Ghana}

\section{Introduction}

(1) most optimistic projections for greenhouse gas emissions, global mean surface temperatures are expected to rise $0.3^{\circ} \mathrm{C}$ to $1.7^{\circ} \mathrm{C}$ by the end of the $21^{\text {st }}$ Century (IPCC, 2013). Whilst higher temperatures are a global concern, increases in surface temperatures are predicted to be greatest in Africa (Collins, 2011), including the greatest change in days when extreme temperatures are likely to impact population health (Garland et al., 2015). Alongside global warming, the planet is also likely to experience higher risk of flooding, especially in Asia and Africa (Hirabayashi et al., 2013). Over the past three decades, there has been a rise in the number of reported severe floods, their cost, and mortality statistics associated with such flood events (Kundzewicz et al., 2013). Flooding is the most frequently occurring natural hazard and ranks only below storms and earthquakes for being the most damaging (Wilby et al., 2012). Flooding affected 2.3 billion people globally between 2005-2014, while extreme heat affected 94 million people in the same period. Extreme heat ranked higher as a cause of mortality in this period, being directly related to 164,000 deaths compared to 157,000 for floods (UNISDR, 2015).

Extreme weather events, linked to climate change, disproportionately affect the urban poor (Gough et al., 2019), hence, low-income settlements have become 'hot spots' of vulnerability to climate change (Wilby, 2007). In many African cities, flood and extreme heat vulnerability have been linked to urban poverty, informality and populations occupying flood and/or 
extreme heat hotspots (Few, 2003), but these issues are usually researched in isolation, rather

than holistically. The few studies that focus on the relationship between informality, poverty and vulnerability are restricted to flooding (e.g. Amoako and Inkoom, 2018). Typically, studies do not include extreme heat events or examine the impacts of these episodes on urban infrastructure, including health service provision. However, this is vital for maintaining health and preventing mortality during such events.

The dual aims of this paper are to (1) explore the vulnerabilities of health services during flooding and extreme heat in two urban areas of Ghana and (2) identify the coping strategies that are being used to build resilience by both health service providers and community members. The local perspectives provided by this study enrich our understanding of the key vulnerabilities, resilience and potential adaptations needed to enhance health service provision in the Ghanaian context. We also consider the transferability of these insights to other low-income communities.

\section{Extreme weather events and health services}

Extreme weather events have direct influences on health outcomes globally (Kovats et al., 2008), although the epidemiological evidence base for this association in Africa is weak (Amegah et al., 2016). As well as directly affecting health, extreme weather events also impact health service provision. The WHO (2018) COP 24 Special Report on Health and Climate Change summarises and maps findings from major studies that have taken place on health adaptation to climate change. No studies were identified for West Africa in this report, despite the region's high vulnerability to both flooding and extreme heat. This is particularly concerning because West Africa currently has the highest number of extreme heat days and 
this number is predicted to continue to rise (Garland et al., 2015). West Africa, therefore, has no regionally specific evidence on which to base plans for adapting health services to climate change. From the major studies reviewed outside of West Africa, the report identifies key areas on which health systems need to focus to be more resilient to climate change. These include investing in adaptation to contribute to achieving the sustainable development goals; growing capacity and engaging with stakeholders; adopting a multisectoral approach; having good measures for monitoring and evaluating changes; and ensuring plans adapt to new knowledge (WHO, 2018).

Studies have been conducted that demonstrate the potential impacts of climate change on health service provision in high-income settings. For example, a review commissioned by the UK Research Council 'Living with Environmental Change' programme, which covered UK literature from 2010-2017 (Curtis et al., 2017), highlighted two areas in which climate change directly affects health. These are via (1) direct infrastructural impacts on service provision; and (2) changes in demand for services during extreme weather events. The review considered the impact of flooding and the effects of extreme cold and extreme heat on health and social care systems, acknowledging the important roles played by community groups when they are well supported. It additionally identified adaptations to make health care systems more resilient, including policies and infrastructure within the health service to manage risks associated with extreme weather (e.g. emergency response systems targeting all levels of health workers). The review further highlighted the need to think beyond health services themselves to consider supporting systems, such as transport and utility services, which are critical for efficient health service functioning. These findings are just as applicable in other regions. 
Specific challenges related to flooding include evacuating patients from facilities; managing interruptions to essential utilities and transport services; keeping patient records safe; controlling risks from fire and electrocution; maintaining access through community outreach services. Furthermore, factors related to extreme heat include difficulties with storing equipment and medicines sensitive to extreme temperatures, as well as maintaining the thermal comfort of hospital buildings despite poor ventilation or design. The review concluded that the effects of extreme weather episodes are unequally distributed, with marginalised groups and especially women disproportionately absorbing the burden of additional care when the health and social care systems fail (Curtis et al., 2017).

Evidence from high-income settings provides a basis for understanding health service provision under climate change but lacks relevant contextual information about the additional urban infrastructural challenges faced in low- and middle-income countries, including the lack of consistent connectivity to essential services (e.g. robust transport infrastructures, electricity, water, refuse collection and sanitation). These factors are important when considering the relationship between climate and health service provision (McMichael et al., 2006). Evidence is needed for West Africa to understand the challenges faced by health services operating with frequent exposure to extreme weather. Such information is vital for strengthening health systems in vulnerable areas and making them more resilient to climate change. The concepts of vulnerability and resilience are both multidisciplinary and defined in numerous ways. Here, we interpret vulnerability in broad terms as the 'sensitivity or susceptibility to harm and lack of capacity to adapt' (Otto et. al., 2017, p.2), whereas resilience generally refers to the ability of a system to maintain the same function and/or structure despite experiencing shocks (Cobbinah and Pouk-Boansi, 2018). These concepts are useful for examining the impact of extreme weather events on health service provision. 
102 Evidence relating flooding to health service provision in an African context is limited. 103 However, a relationship has been identified between flooding and access to health services, 104 and flooding and mental health. During wet seasons, access to health services is reduced 105 (Makanga et al., 2017; Wilunda et al., 2017). In Mozambique, for example, the number of people living more than one hour's walking distance from health facilities increases by as much as 40 percent during flood events due to excessive water on roads and pathways (Makanga et al., 2017). Impaired access can be especially detrimental for people with chronic conditions requiring frequent treatment, such as those with mental health issues. Flooding also has psychosocial consequences, which lead to distress and potentially poor mental health (Harris et al., 2018).

Hospitals house some of the most vulnerable members of society from age groups most at risk from extreme heat, such as the elderly, pregnant mothers and children. These groups often present with symptoms of extreme heat, including fever, or conditions that are vulnerable to the effects of heat, such as cardiovascular events (Crandall and Wilson, 2015). Hospital buildings can be an uncomfortable thermal environment for patients and staff during extreme temperatures, with the potential to exacerbate health problems. Although outdoor temperatures are rising across the African continent, little is known about the indoor temperatures that African patients and staff are exposed to. Only one study has been identified that recorded such data, and that was for outpatient waiting rooms in the northern region of Limpopo Province, South Africa. This research showed that indoor temperatures in the waiting areas were typically 2 to $4^{\circ} \mathrm{C}$ higher than outside air temperatures and that some clinics exceeded maximum temperatures of $38^{\circ} \mathrm{C}$ (Wright et al., 2017). 
Health services need to be able to respond to extreme weather in order to be resilient and

127 provide quality services. Hanefield et al. (2018) identified common aspects of resilience in

128 health services in the face of different shocks in low- and middle-income country contexts, including extreme events (such as flooding and tsunamis) and an outbreak of the Ebola virus. They found that governance plays a fundamental role in the success of responses to disasters. Moreover, a lack of intersectoral governance, especially between the health sector and climate services providers, was identified as a weakness in the resilience of the health system to climate shocks.

\section{Study context and methodology}

Ghana was selected as the primary case study for this research because it is in a climatically vulnerable region of sub-Saharan Africa and has a large and growing urban population, estimated at above 50 percent of the total population (Yeboah et al., 2013). Many of the findings from Ghana, however, could be transferred to other similar vulnerable urban areas in low- and middle-income countries, especially in sub-Saharan Africa. Furthermore, Ghanaian cities are vulnerable to two extreme weather-related events: flooding and extreme heat (Codjoe et al., 2014). Over the past five decades, Ghana has been affected by at least 17 major floods, which have cumulatively impacted more than 16 million people and resulted in at least 444 deaths, with Accra recording the most damage (Figure 1). Within the past five years, major flooding events have affected over 100,000 people in the Greater Accra and northern regions, where Accra and Tamale are respectively located. The most prominent episodes include a major flood event in Accra on June 3, 2015, which killed around 150 people, displaced over 8,000 and injured numerous others (UN Country Team Ghana, 2015). 
In Tamale, floods following a torrential 6-hour downpour on July 25, 2017 devastated many parts of the city and resulted in two fatalities. The worst affected communities were Gumani and Ward K. Two major health centres (Tamale Teaching Hospital and the Central Hospital) and properties worth millions of Ghana Cedis were destroyed. These flood events in Tamale and Accra serve as reference points for health facilities when talking about the effect of floods on health service provision.

\section{INSERT FIGURE 1 ABOUT HERE}

In Ghana, annual mean temperatures increased by over $1^{\circ} \mathrm{C}$ between 1960 and 2010 (Amoako \& Boamah, 2014). The National Climate Change Policy of Ghana acknowledges the increased risk of heat stress and drought-related mortality, particularly in northern Ghana (Ministry of Environment, Science, Technology and Innovation, 2012). Unlike for flooding, large scale extreme heat-related disasters have not been documented or experienced except for their association with cerebro-spinal meningitis outbreaks in northern Ghana (Codjoe \& Nabie, 2014; Kwarteng et al., 2017). However, studies on perceptions about climate change show that community members perceive excessive sunshine and heat in urban Accra (Codjoe et al., 2014), while analysis of temperature data show steadily high and increasing temperature in northern Ghana (Yiran \& Stringer, 2016).

Two cities in Ghana were selected for this research: Accra, the capital and largest city located in the south of the country; and Tamale, a rapidly growing intermediate-sized city in northern Ghana. Both cities have a long history of extreme heat and flood hazards, with several devastating events recorded since the 1950s (Amoako and Inkoom, 2018; Karley, 2009; Rain et al., 2011). Such extreme heat and flood events have had greatest impacts on poor urban 
communities (Douglas et al., 2008; Amoako and Inkoom, 2018). In each of the cities, four

177 low-income communities were purposively selected for the research based on their population density, informality and vulnerability to flood and extreme heat events (Table 1). The four flood-prone communities were Odawna and Bortianor in Accra, and Gumani and Ward $\mathrm{K}$ in Tamale. The four extreme heat prone communities were Agbogbloshie and Alajo in Accra, and Kukuo and Lamashegu in Tamale. Some of these areas experience both floods and extreme heat but have been categorised according to whether they are more heat or more flood prone. Within each settlement, a 'Champion' - who became our key contact person and assisted with all stages of the research - was selected by community leaders. These communities were recruited into a larger study that was looking at the effect of extreme weather events on services, livelihoods and poor urban communities (Gough et al., 2019). The study was approved by the Ethics Committee for the Humanities (ECH) of the University of Ghana with reference number ECH 109/17-18.

INSERT TABLE 1 ABOUT HERE

In this paper we focus on the effect of extreme weather on health service provision. For each settlement, with the help of the community champions at least one health service frequented by the residents of the different communities was purposely selected to cover both public and private facilities serving the urban poor in each of the study cities. All health services identified were sent an initial letter inviting the facility to take part in the research, which was followed up by a visit from one of the research team to gain consent from their respective directors to participate in the research. No facilities approached declined to take part in the research. A range of approaches and methods were adopted to collect data including 
temperature measurements in the facility, semi-structured interviews with leaders within the facilities, and field observations.

\subsection{Temperature measurements in health facilities}

Tiny tag Transit 2 thermistors were installed in health clinics and hospitals during May-July 2018 to monitor air temperatures experienced by staff and patients. These small devices automatically detect and record air temperatures at prescribed sampling intervals and have a battery life of about two years so only require periodic attention for downloading data. In total 12 tiny tags (1 laboratory, 2 labour wards, 2 out-patient departments, 5 waiting rooms and 2 children's wards) were deployed inside health facilities from which 10-minute temperature data were downloaded every six weeks. These data were used to derive daily minimum, mean and maximum temperatures for each day within the monitored period. The lowest daily minimum, daily mean, and highest daily maximum were then calculated for the period as a whole. Use of daily means helps to eliminate short-term fluctuations due to for example intense rainfall, however, sub-hourly data are presented below for some of the hottest days recorded in the study period.

Another 50 tiny tags were installed in homes within the selected low-income communities to gain insight into temperatures experienced by staff and patients when away from health facilities. Tiny tags (2) were also placed alongside thermometers in meteorological weather stations at Accra and Tamale airports. Comparison of temperatures in health facilities and homes/workplaces with ambient temperatures at meteorological stations reveals the extent to which 'official' outdoor records understate the true severity of heat experienced by people in their daily lives. Moreover, temperatures measured at meteorological stations also help to 
benchmark the effects of variations in building size, materials and shading on indoor

226

227

228

229

230

231

232 temperatures against a common reference point. Finally, meteorological station records covering multiple decades can be used to situate the monitored period in a longer context.

\subsection{Key informant interviews}

Semi-structured interviews were held with the health service providers to investigate how their services are impacted by flooding and extreme heat events, as well as current systems for disaster preparedness, and the benefits of being able to accurately forecast extreme weather events. Interviews were conducted in a total of 16 health facilities with 18 participants (two joint interviews at the request of the facilities concerned to have the people present with the insight to cover all of the topics in the interview guide), including public and private clinics, hospitals and pharmacies. Each interview lasted between 30 minutes and one hour. The ways in which the problems faced by the service providers are mutually reinforcing was explored. All of these informants, and their directors, gave informed consent to participate in the research.

\section{INSERT TABLE 2 HERE}

\subsection{Data coding and analysis}

All interviews were transcribed and then thematically analysed and organised with NVivo. The approach taken for analysis was deductive (theory driven), using the concepts of resilience (Cobbinah and Pouk-Boansi, 2018) and vulnerability (Otto et al., 2017). Initially SNAC, PLG, EFA, and MAA coded the transcripts using these concepts. Each transcript was 
considered by at least two of the author team and differences in opinions regarding the

251

252

253

254

255

256

257

258

259

260

261

262

263

264

265

266

267

268

269

270

271

272

273

274 themes and coding were reconciled through discussions and consensus. The emerging findings from this exercise were discussed at a meeting of the wider project group, including KVG, RLW, RK and PWKY, to ensure that aspects of vulnerability or resilience were not being missed. The coding structure was revised accordingly and the finalised coding structure was applied using the NVIVO 11 software. Thematic analyses are presented in this paper using the overarching concepts of vulnerability and resilience separately to organise the findings.

\section{Results}

The findings from the various methods are presented and discussed here, beginning with vulnerability and resilience to floods followed by extreme heat. The main themes under which results are presented are: (1) vulnerability of health facility and equipment (2) disruption of access to healthcare.

\subsection{Flood vulnerabilities}

\subsubsection{Vulnerability of health facilities and equipment to flooding}

Floods are reported to impact low-lying wards and health facility sites where there are blocked open drains near wards with permanently open windows. A severe flooding event in 2017 unexpectedly brought flood water into one of the Tamale facilities in this study. The rain was so intense that water entered the wards, halting all activities as staff had to clear up and disinfect. Similarly, the Administrator of one of the Accra facilities indicated that they 
lost a substantial amount of medicine, supplies and equipment, including refrigerators, due to floods in 2015, as their warehouse was in a flood-prone area.

It is not only the equipment and supplies in health facilities that are impacted by flooding but also healthcare operations can be greatly disrupted. In Tamale, health officials stated that unpaved surfaces between hospital wards become muddy during the rainy season, impeding movement and making it hard for staff to work and maintain hygiene levels, as well as move patients. Medical staff members reported having accidents on muddy surfaces and subsequent cleaning of wards after a flood to remove mud is a challenge, as a nurse in Tamale explained:

As you can see our floor outside is not cemented and the ground is clay so when it rains this place becomes very muddy. This makes it difficult to move quickly from one ward to another. The problem is even worse for the workers who push the sick people in their wheelchairs and the stretcher. Sometime last year after a heavy downpour, one of our nurses who was running from the children's ward to the pharmacy to get a medicine to handle an emergency case slipped and fell on the muddy surface and broke her leg. We also clean the wards several times a day during the rainy season because people walk into the wards with mud under their shoes. The cleaning materials cost us a lot of money and cleaning also takes a lot of time. (Nurse in Charge, Tamale)

Another vulnerability reported was that stand-by generators at health facilities became unusable during extreme flooding. The Administrator of one of the Accra health facilities indicated that they relocate movable equipment upstairs when the rain starts. However, they are unable to move the generator since it is fixed, and if the flood waters reach a certain level 
the generator becomes unusable. In other facilities it was reported that in situations where back-up generators could be deployed, there can be disruption in fuel services preventing their use. Furthermore, electricity supplies to the health facilities are interrupted during floods because power companies disconnect the power to avoid electrocution. Service providers rarely issue power outage notices. The Medical Officer in Charge of one of the Accra health facilities commented:

$$
\begin{aligned}
& \text { You know we have our own term which is called 'dumsor'. It is about our electricity } \\
& \text { which is always on and off. We don't have a stable system where the power can be on } \\
& \text { for weeks without experiencing an interruption. It is always like that so most facilities } \\
& \text { you see here always have a standby generator. (Medical Officer in Charge, Accra) }
\end{aligned}
$$

The impact of flood events regarding health service provision include: losing bed spaces where mattresses have been placed on the floor in crowded facilities (these become unusable during a flood), relocating patients upstairs where possible, moving equipment and pharmaceutical supplies to avoid damage, and having to nurse in knee-deep flood waters. Additional effects include lack of stocks in small pharmacies to build resilience when extreme events happen, and time and resources spent renovating buildings after flooding.

\subsubsection{Disrupted access to health services}

Flood events increase demand for both physical and mental health services because of the higher prevalence of disease and associated mental health problems. Hence, floods exacerbate an already overstretched health service, making a lack of beds and referral even more difficult than would normally be the case. This is particularly difficult in poor informal 
settlements because patients cannot afford the higher transport costs to larger hospitals, especially if the local facility is full when the patient arrives and transport costs have already been paid. The Nurse in Charge of an Accra out-patient health facility indicated how patients are not detained for longer than 24 hours before being referred to higher tier facilities. During extreme flooding events, even these higher tier hospitals do not have enough beds, thus, patients are transported from one hospital to another until a health facility with a vacant bed is found. One Nurse in Charge reported going around searching the whole night with a patient to find an available bed. This story was not unique but was a recurring theme in government and private facilities in both Tamale and Accra. When roads become blocked with floodwaters, searching for a bed can be even more problematic. The "no bed" syndrome experienced particularly during extreme flooding events was summarised as follows:

\section{For me the no bed has now become like a song. Sometimes I say it's a song that I} hate. I ask when this song will stop. They say no beds, no beds. So it is quite a challenge, big challenge. They say we should call, sometimes we call them and they say no bed. They sing the same song, no beds, no beds. It is quite a big issue. Sometimes they will ask if the patient can sit in a chair instead of sleeping on a bed when admitted in the facility. If he can't then he can't come. (Medical Officer in Charge, Accra).

Communities can become isolated from health services during floods, which can be a problem for those on regular medication, especially for mental health illnesses, diabetes and hypertension where prescriptions are often not given for many days. In some instances, community members carry patients through floods until they reach a safe road to travel to reach health facilities. The Medical Officer in Charge at a Tamale health facility reported that 
people fear the rains and flooding events due to previous bad experiences, which prevent them leaving their homes for necessary medical appointments. In one of the Accra health facilities, it was reported that communities living nearby who would normally use the facility were not able to because the flood waters make the road to the facility impassable:

When it rains heavily the town is separated into two and people get stuck on one side. You see, there is no proper bridge on the road so when it rains the main road gets flooded, and people are unable to go from one side to the other. How then can they come to the clinic? They can't even go about their daily activities. And the pressure with which the water flows, you should see it for yourself. Even a 4 by 4 vehicle cannot cross it. (Medical Officer, Accra).

There are extra health costs associated with floods because of injury and greater incidence of diseases. Residents may decide to use cheaper service providers during floods because working hours and earnings are reduced. Those without health insurance are especially vulnerable. The medical superintendent at one of the health facilities in Accra indicated that as the services of traditional healers are cheaper, more likely to work for credit, and more locally available, they are more frequently used during floods:

The type of patients we have here are mostly poor and I see that during the rainy season their businesses are affected and so they earn less money. So during the rainy season some of them are unable to pay for our services although our charges are very minimal. It is during this time that they visit the spiritual and traditional healers who charge even less than us and also give them credit. But, remember these traditional healers are less effective so on some occasions some of these patients come back to 
our facility with complicated cases from their encounter with these spiritual and traditional healers. (Medical Officer in Charge, Accra).

The emergency response to floods has largely focussed on physical health, but it was also widely reported that communities also need support for their mental health because of the stress caused extreme floods. The loss of lives and property, as well as not having safe and dry places to sleep during floods, result in a lack of sleep and increases stress.

\subsubsection{Building resilience to floods}

Respondents in both Accra and Tamale reported various autonomous adaptations that build resilience to the perennial problem of health service delivery during floods. These adaptations are both anticipatory and reactionary. Adaptations undertaken include mobilisation of the local population to clear rubbish, so drains do not become blocked, and scooping water back into drains after floods. As the Medical Officer at one of the Accra health facilities explained: Accra)

Other adaptations include building a new raised area for the generator, pharmacy and other immovable equipment to protect them from floods, plus building walls to stop flood waters 
entering the facility. In a health facility in Accra, the Administrator indicated their future plans:

It's a small space so you need to be cautious as to how you utilize it. So we felt that in the long term there should be a provision for a building that there wouldn't be rooms under because of the flood. We could leave the underneath as a car park. That's what we intend doing. The pharmacy will also be moved upstairs. (Health Facility Administrator, Accra).

Respondents recommended additional measures to manage flood impacts in their cities. For example, the need for improvements in the drainage system so it has the capacity to carry floodwaters, and the need for more control over some of the internally generated funds in hospitals, in order to be able to invest in making the facility more resilient to flooding (e.g. paving outside floor surfaces). Participants reported private hospitals, even small ones, having greater control over their budgets compared to public hospitals, and being able to make decisions that build resilience to extreme weather events, such as installing and covering drains.

\subsection{Extreme heat vulnerabilities}

Turning to extreme heat events, this section provides contextual information about the high temperatures experienced within the health facilities, both on average and during selected heatwave episodes. The study period was unremarkable in terms of maximum temperatures recorded at the two official weather stations since the 1960s. Hence, the results presented below are not as extreme as they might have been in hotter years, such as 2016 (both cities). 
425 Our data also demonstrate how reliance on weather station data (as is the norm) can underestimate the true exposure to indoor heat (Nguyen and Hockery, 2016).

427

428

As expected, all health facility spaces sampled were on average warmer than the reference meteorological site, especially at night. The lowest temperature recorded in any of the health facilities was $23.7^{\circ} \mathrm{C}$ (Tamale), while the highest was $38.2^{\circ} \mathrm{C}$ (Tamale). Some health facilities were more than $6^{\circ} \mathrm{C}$ warmer at night than the meteorological site. This is due to a combination of greater thermal inertia of the buildings and local influence of the urban heat island. Heat islands form because, when compared with vegetated rural areas, the built environment retains more solar energy during the day and has lower rates of radiant cooling at night. Dense urban areas also tend to have lower wind speeds and less evaporative cooling from plants, leaving more energy for surface warming. Air conditioning units, transport systems, cooking, and industrial facilities add further heat. Within Agblogbloshie (Accra), the urban heat island can elevate local outdoor temperatures by more than $2.5^{\circ} \mathrm{C}$ at night compared with the reference meteorological station (M1c).

Figure 2 shows the mean, maximum and minimum indoor temperatures recorded at health facilities in the two cities. Overall, mean indoor temperatures for health facilities were $\sim 1.7^{\circ} \mathrm{C}$ warmer in Tamale than Accra, though mean night temperatures were slightly cooler $\left(\sim 0.5^{\circ} \mathrm{C}\right)$ in Tamale than Accra.

\section{INSERT FIGURE 2 HERE}

In Figure 3, a comparison of indoor temperature at one health facility in Accra compared to all the other health facilities in the city is made. The figure shows how afternoon rainfall can 
bring temporary cooling, as seen for the Out-Patients' Department waiting area, which is on

451

452

453

454

455

456

457

458

459

460

461

462

463

464

465

466

467

468

469

470

471

472

473

474 the ground floor and in an open area, though not to the extent seen at the reference meteorological station (M1c).

\section{INSERT FIGURE 3 HERE}

Figure 4 compares indoor temperature for one health facility in Tamale with the other health facilities in the city. The very high night-time temperatures relative to the meteorological station are particularly noteworthy on the hottest day recorded. Peak temperatures in the health facilities can sometimes lag peak temperatures at the meteorological site, again due to the thermal inertia (heat-retaining properties) of large buildings.

\section{INSERT FIGURE 4 HERE}

\subsubsection{Vulnerability of health facilities to extreme heat}

Respondents asserted that extreme temperatures make conditions hard for both patients and staff. As some facilities were not built for purpose, they have very poor ventilation which exacerbates the heat. For example, one facility had been converted from old residential bungalows into a health facility and the windows providing ventilation were too small. Fans are not very effective, especially once the temperature is over $34^{\circ} \mathrm{C}$, and cost money to run. As the Medical Officer in Charge of a health facility in Tamale explained: air-conditioners are only used in the pharmacy and operating theatre. You know 

delivery. (Medical Officer in Charge, Tamale).

Extreme heat can impact working conditions for health workers and limit their ability to discharge their duties. For instance, extreme heat causes staff to sweat, which is especially problematic during surgery because of the risk of infection due to sweating into open wounds. A surgeon working in a health facility in Tamale stated that,

As for the extreme heat, normally, everybody sweats during that time and then if you come to my unit where we normally attend to open wounds you see that when you are sweating that is not the best time. The time you are sweating profusely to open somebody's wound you are exposing it to infections, so it affects us. (Surgeon, Tamale).

An additional challenge health facilities face is disruption to infrastructure during extreme heat. Lack of water due to associated low rainfall and power outages, due to increased energy demand, result in both water and electricity supplies being interrupted. Some of the smaller health facilities which deliver outpatient services face additional problems. For example, carrying water to the primary health centre, which does not have a piped supply on site, becomes harder during extreme heat. Thus, feverish patients are unable to shower regularly and sometimes there is no water to flush toilets. Lack of water also makes it difficult to maintain hygiene. In smaller health facilities where there are no generators, the pharmacy loses refrigeration when there is a power outage; if supplies are not quickly moved to a facility with power, drugs are damaged. This can also be a challenge for vaccination cold chain storage, as the Nurse in Charge of a health facility in Tamale indicated: 
The heat also brings challenges with the storage of our drugs. I wanted to get some HIV drugs for the facility because we do the counselling and testing here but they facility in Accra claimed that:

We use more power during the heat and the pre-paid electricity service is too expensive for us. We have a generator which helps us a lot with our services here sometimes. However, this is a small facility and we don't generate enough money to buy fuel all the time for a generator. Sometimes in the evening when you have to attend to the patients, set IV's, give medications and all that you don't see very well and so we use our mobile phone lights. (Nurse, Accra). 
526 Lack of shade for waiting patients is a problem in one smaller primary health centre. This was the same facility that recorded a maximum temperature of $38.2^{\circ} \mathrm{C}$, even in shade. This facility is providing maternal and child health services and a large proportion of their clients are either heavily pregnant or new-born infants who are vulnerable to the effects of extreme heat. Once patients are admitted to most facilities, overcrowding on the wards, especially during the peak dry season, exacerbates heat. Instances of putting more than one patient in a bed on the children's ward, or placing mattresses on the floor between beds, reduces the opportunity for air flow and increases the temperatures experienced by patients who struggle to sleep, and children often cry. Some patients even sleep outside during extreme heat, which increases risk of mosquito borne diseases, such as malaria. Some of the challenges facing health facilities during extreme heat are illustrated by the following quote:

There were reports of patients paying for private facilities even when they had a national health insurance card because of the long waiting times at the public facilities. This increases the financial stress on households, who are already stretched because work hours may be 
549 reduced in extreme heat because the temperature conditions are not conducive to manual 550 labour (Gough et al., 2019).

551

\subsubsection{Challenges beyond the health facility for health workers in extreme heat}

553

554

555

556

557

558

559

560

561

562

563

564

565

566

567

568

569

570

571

572

573

Not only do health staff work under hot conditions, they also experience extreme heat at home. The challenge of sleeping at night increases fatigue whilst at work, elevating the risk of errors. As a surgeon from one of the Tamale health facilities explained, 'Sometimes you know when the weather is so hot you don't rest enough so you come to work still looking tired'. Figure 5 reveals how homes with metal roofs are on average notably warmer indoors during daytime than those with asbestos or thatch roofing, but metal roofed homes tend to cool down faster at night (see Gough et al., 2019 for further information). All homes where temperatures were recorded, however, are on average warmer than the reference meteorological site, which can be explained by the density of buildings and the urban heat island effect. Many of the staff working in the health facilities sleep in buildings such as these.

\section{INSERT FIGURE 5 HERE}

\subsubsection{Resilience to extreme heat}

Several adaptation strategies were identified that increase resilience to extreme heat conditions. Some health facilities have installed large windows and doors with nets to increase ventilation during extreme heat. Private facilities report fewer problems with power cuts as they can afford fuel to run generators during power outages; if public hospitals had the 
same resources to run generators, they would benefit greatly during extreme heat. Larger government facilities and private hospitals reported that installing water pumps resulted in fewer problems during periods of water shortages. Polytanks (storage tanks) are also used to increase water storage and reliability. Other adaptation strategies reported included: ensuring fuel is available for generators, making torchlight available for emergency surgery during power outages, and using generator backup for refrigeration. The need for advanced warning systems for extreme heat events was stated by several health facilities. A Medical Officer in Tamale indicated how health facilities could take control of warning systems if they were empowered to:

We do not get any advance warning about the heat, yet it is very important. We only hear announcement in the news by the Ghana Meteorological Services. Recently, there was a warning about the outbreak of CSM [cerebrospinal meningitis] by the Ghana Health Service. It would be good to have some of your devices [Tiny Tags] so that we can also monitor the heat and know what to do in the future. (Medical Officer, Tamale).

\section{Discussion}

This study presents the views of stakeholders about the numerous negative effects of flooding and extreme heat on health service provision in four poor urban communities in Ghana. Health facilities are affected in ways that compromise healthcare delivery, as well as quality of life of residents. Poor building conditions, unstable power supply, and poor sanitation and hygiene conditions are socioeconomic features of urban poor communities, which expose residents to environmental hazards and restrict their access to quality health care. Thus, 
601

602

extreme weather events present significant challenges for health service delivery to informal poor urban communities.

Flooding directly impacts infrastructure, service delivery and health conditions of patients in health facilities in both Accra and Tamale. During periods of flooding, essential utilities including equipment, surgical apparatus, disposables and medicines become damaged. Where possible, equipment is moved, though doing so disrupts the provision of services by health workers. When health facilities are flooded, in-patients have the additional burden of having to move to higher levels or being referred to other hospitals. Walking on muddy surfaces also presents injury risks to health workers and patients. Patient transfer to other facilities is affected by the poor road network in times of flooding. The disruption to health service provisioning at the health facilities reflects and worsens the already inefficient healthcare system in poor urban informal settlements. Moreover, electricity supply to health facilities may be cut because poor informal communities have a higher risk of electrocution from flooding (Gough et al., 2019).

Flooding also affects demand for health services in the communities and is associated with mental health problems. The disruption of housing conditions and daily living arising from devastations caused by flooding is traumatising for residents. The psychological distress associated with flooding can further exacerbate injuries and existing physical conditions for patients (Alderman et al., 2012). Flooding disrupts economic livelihoods in the informal sector, resulting in lower wages and less potential for health expenditure, which compromises the quality of healthcare that people can access during flooding. 
623 Extreme heat is another environmental challenge that stresses the vulnerable health 624 infrastructure in poor urban areas. Health facilities were notably warmer indoors than nearby 625 official weather stations (which are typically used for evaluating health impacts and 626 calibrating heatwave forecasting systems). Higher indoor temperatures may partly be due to 627 urban heat islands associated with the built environment (Johnson et al., 2012) but they may also reflect poor building design, especially in health facilities not built for such purposes. Artificial ventilation (fans and air conditioners) can be costly to run or may be faulty. During periods of extreme heat, there is greater pressure on energy supply from the increased demand for energy for cooling, and the disrupted power supply can affect the existing weak system for storage of medical supplies. Crowding in the health facilities exacerbates the already hot and humid conditions for both patients and health workers. Beyond the facilities, health workers who reside in low-income urban communities exposed to extreme heat may face other challenges that impact the quality of the service they provide. Extreme heat may alter sleep patterns and behaviours, ultimately affecting exposure to mosquito bites and causing sleep deprivation.

Figure 6 illustrates the interactions and pathways through which extreme weather events impact health care in urban poor areas of Ghana. This framework indicates that flooding and extreme heat interact with poor conditions in urban areas to disrupt health service infrastructure, as well as community infrastructure and social organisation. Poor access to social amenities underlies the vulnerabilities created by flooding and extreme heat in informal settlements. Infrastructural deficits present unique health challenges, which amplify the effects of flooding and extreme heat on population health. 
649 Disruptions in urban infrastructure and social organisation lead to injuries, accidents, stress and trauma, and facilitate the spread of vector-borne diseases. These lead to an increased demand for health care, placing a burden on health facilities, which are themselves affected by the extreme weather events. As Curtis et al. (2017) found in the UK, it is low-income families, and women in particular, who bear the brunt of taking on additional care responsibilities when health facilities are overstretched. Communities and health systems are not passive in these situations; rather they undertake a range of activities to enhance their resilience. Health facilities adopt measures to minimise the disruption to service delivery, while communities mobilise efforts towards controlling floods and minimising heat. The strategies adopted by communities determine the sensitivity of urban systems to extreme weather conditions, as well as the quality of health care delivery.

A key objective of Ghana's 2012 National Climate Change Policy, with its action programme of implementation related to emergency preparedness and climate-proof health infrastructure, is to "strengthen and operationalise the health-related components of disaster risk reduction plans" (Ministry of Environment, Science, Technology and Innovation, 2015). The main actions under this policy objective are targeted at reducing casualties from impacts of extreme weather events, as well as managing acute health impacts of climate change. None of the proposed actions deals with improving the resilience of the health system for service delivery. Similarly, Ghana's Ministry of Health in its 2016 National Quality Healthcare Strategy identifies ways to improve quality healthcare at different levels of healthcare provision but does not mainstream climate impacts into health infrastructure. This is particularly problematic in poor urban areas, where, as this paper shows, healthcare provision

671 is disrupted by the impacts of extreme weather conditions. The Fifth Assessment Report of 672 the IPCC on the impacts of climate change on health, identifies the important roles played by 
673 health care services in improving health (IPCC, 2014). Three sources of health vulnerability 674 are identified including: direct heat- and cold-related impacts, ecological disruptions and

675

676

677

678

679

680

681

682

683

684

685

686

687

688

689

690

691

692

693

694

695

696

697 social responses. The recommendations, however, are based on evidence from Europe, hence the types of disruption to healthcare provision shown in this paper are barely discussed. Future assessments of climate change impacts on health, and resilience building programmes and policies in the health sector, should consider the impacts of extreme weather events on healthcare provision, particularly in poor urban communities in low- and middle-income settings.

While this paper discusses flood and heat in isolation, there could be instances when both extreme events occur in rapid succession. This compound hazard could be especially impactful, and may be more likely under global warming with more intense rainfalls (Zscheischler et al., 2018). Other work has highlighted the potential threat of widespread loss of air-conditioning due to storm-related power outages, followed by a deadly heatwave (Mathews et al., 2019).

\section{Conclusion}

The evidence presented in this paper shows that flooding and extreme heat negatively impact healthcare delivery and quality of life in informal urban settlements in numerous ways, revealing the complexity of the extreme weather event/urban health nexus. By focussing on urban Ghana, this research contributes much needed evidence from the African region, which is experiencing more extreme weather events.

Given that health facilities in poor urban settlements may be poorly sited and lack capacity, flooding has direct infrastructural impacts, disrupting operational activities, causing negative 
health consequences for patients and creating difficult working conditions for staff. Poor

699

700

701

702

703

704

705

706

707

708

709

710

711

712

713

714

715

716

717

718

719

720

721

722 building design/materials and unstable power and water supplies at health facilities mean that extreme heat induces health worker stress and compromises the quality of service delivery. Importantly, this paper shows how official meteorological station records can understate the extreme temperature conditions experienced within some health facilities, which can be extremely challenging for patients and staff. Extreme weather conditions are also associated with an increased demand for healthcare. To build resilience and cope with various health challenges, communities employ measures to curb the incidence and effects of flooding, while health facilities engage community members to control flooding, as well as adopt physical infrastructural adaptations to try to reduce the impacts of flooding and extreme heat.

It is important to note that, even though there may be similarities in terms of the nature of the impact of flooding and extreme heat on health globally, there are differences in the scale of the impact because in high-income settings, such as the UK (Curtis et al., 2017), extreme weather events disrupt a better resourced standard of service delivery and supporting infrastructure. As this paper shows, in lower-income contexts, the systems lack resources and have aging and over-stretched infrastructure, which extreme weather events further exacerbate.

In order to build more resilience into the health system in Ghana, there is a need to explore design changes to reduce the impact of flood events, including: building raised paths, improving drains and toilet facilities, improving ventilation facilities, and tiling mud floors. Government facilities, however, can only implement these initiatives if they are allocated additional resources. Contingency planning for power outages that are likely to accompany flood and heat waves are also required. Such strategies require power companies to give more 
723

724

725

726

727

728

729

730

731

732

733

734

735

736

737

738

739

740

741

742

743

744

745

746

747

38

9

notice of outages to ensure enough fuel can be stock-piled to run generators. Having good battery-operated torches available as backups, especially for critical areas of operation like emergency surgery procedures, as well as exploring the potential for solar powered air conditioners are additional strategies. Furthermore, improved coordination is needed to locate free beds in health facilities. Finally, effective early warning systems for flooding and heat waves, that are embedded in existing communication structures, are essential for improving preparedness and reducing the impact of extreme weather events. However, not only does the reliability of forecast warning need to be high so that warnings are not ignored, health facility managers and communities need guidance on what to do in response to this information for such warnings to be effective.

These proposed strategies indicate the importance of conducting further collaborative research with professionals in the healthcare sector, water and energy utilities, and urban governance, in order to better understand how they can be implemented. Such knowledge would not only be invaluable for health facilities in Ghana but across the global South.

0




\section{References}

749

750 Alderman, K., Turner, L. R., Tong, S., 2012. Floods and human health: a systematic 751 review. Environment International. 47, 37-47.

752

753 Amegah, A.K., Rezza, G., Jaakkola, J.J.K., 2016. Temperature-related morbidity and 754 mortality in Sub-Saharan Africa: a systematic review of the empirical evidence. Environment 755 International. 91, 133-149.

756

757 Amoako, C., Inkoom, D.K.B., 2018. The production of flood vulnerability in Accra, Ghana: 758 re-thinking flooding and informal urbanization. Urban Studies. 55(13), 2903-2922.

759

760 Cobbinah, P.B., Poku-Boansi, M., 2018. Towards resilient cities in Ghana: insights and 761 strategies. Futures, 101, 55-66.

762

763

Codjoe, S. N. A., Nabie, V. A., 2014. Climate change and Cerebrospinal Meningitis in the 764

Ghanaian Meningitis belt. International Journal of Environmental Research and Public 765 Health, 11(7), 6923-6939. https://doi.org/10.3390/ijerph110706923

766

767

Collins, J.M., 2011. Temperature variability over Africa. Am. Meteorol. Soc. 24, 3649-3666. 768

769 Crandall, C.G., Wilson, T.E., 2015. Human cardiovascular responses to passive heat stress. 770 Compr. Physiol. 5(1), 17-43.

771 
Curtis, S., Fair, A., Wistow, J., Val, D.V., Oven, K., 2017. Impact of extreme weather events and climate change for health and social care systems. Environmental Health. 16 (Suppl 1), 128. DOI 10.1186/s12940-017-0324-3.

Douglas, I., Alam, K., Maghenda, M., Mcdonnell, Y., McLean, L., Campbell, J., 2008. Unjust waters: climate change, flooding and the urban poor in Africa. Environment and Urbanization. 20(1), 187-205.

Few, R., 2003. Flooding vulnerability and coping mechanisms: local responses to a global threat. Progress in Development Studies. 3, 43-58.

Garland, R.M., Matooane, M., Engelbrecht, F.A., Bapope, M.M., Landman, W.A., Naidoo, M., Wright, C.Y., 2015. Regional projections of extreme apparent temperature days in Africa and the related potential risk to human health. Int. J. Environ. Res. Public Health. 12, 1257712604.

Gough, K.V., Yankson, P.W.K., Wilby, R., Amankwaa, E., Abarike, M., Codjoe, S.N.A, Griffiths, P., Kaba, C., Kasei, R., Kayaga, S., 2019. Vulnerability to extreme weather events in cities: implications for infrastructure and livelihoods. Journal of the British Academy.

Hanefeld, J., Mayhew, S., Legido-Quigley, H., Martineau, F., Karanikolos, M., Blanchet, K., Liverani, M., Mokuwa, E.Y., McKay, G., Balabanova, D. 2018. Towards an understanding of resilience: responding to health systems shocks. Health Policy and Planning. 33, 2018, 355367. 
797

798

799

800

801

802

803

804

805

806

807

808

809

810

811

812

813

814

815

816

817

818

819

820

Harris, D., Wurie, A., Baingana, F., Sevalie, S., Beynon, F., 2018. Mental health nurses and disaster response in Sierra Leone. The Lancet. 6, e146-e147.

Hirabayashi, Y., Mahendran, R., Koirala, S., Konoshima, L., Yamazaki, D., Watanabe, S., Kim, H., Kanae, S., 2013. Global flood risk under climate change. Nature Climate Change. 3, 816-821.

IPCC. 2013. Climate Change: The Physical Science Basis: Technical Summary. Intergovernmental Panel on Climate Change.

Johnson, D. P., Stanforth, A., Lulla, V., Luber, G., 2012. Developing an applied extreme heat vulnerability index utilizing socioeconomic and environmental data. Applied Geography, 35(1-2), 23-31. https://doi.org/10.1016/j.apgeog.2012.04.006

Karley, N.K., 2009. Flooding and physical planning in urban areas in West Africa: situational analysis of Accra, Ghana. Theoretical and Empirical Researches in Urban Management. 13(4), 25-41.

Kouadio, I. K., Aljunid, S., Kamigaki, T., Hammad, K., Oshitani, H., 2012. Infectious diseases following natural disasters: prevention and control measures. Expert Review of AntiInfective Therapy, 10(1), 95-104. https://doi.org/10.1586/eri.11.155 
822 Kundzewicz, Z.W., Kanae, S., Seneviratne, S.I., Handmer, J., Nicholls,N., Peduzzi, P., 823 Mechler, R., Bouwer, L.M., Arnell, N., Mach, K., Muir-Wood, R., Brakenridge, G.R., Kron, 824 W., Benito, G., Honda, Y., Takahashi, K., Sherstyukov, B., 2013. Flood risk and climate 825 change: global and regional perspectives. Hydrological Sciences Journal. 59(1), 1-28.

827 Kwarteng, A., Amuasi, J., Annan, A., Ahuno, S., Opare, D., Nagel, M., Vinnemeier, C., May, J., Owusu-Dabo, E., 2017. Current meningitis outbreak in Ghana: Historical perspectives and the importance of diagnostics. Acta tropica. 169, 51-56.

830

McMichael, A.J., Woodruff, R.E., Hales, S. 2006. Climate change and health: present and future risks. The Lancet. 367, 859-869.

833

834 International Journal of Health Geographies. 16, 1-16.

838

839

Ministry of Environment Science and Technology. (2012). Ghana National Climate Change

840 Policy. Accra, Ghana: Government of Ghana.

841 Ministry of Environment, Science, Technology and Innovation, Republic of Ghana. (2015).

National Climate Change Policy Action Programme for Implementation: 2015-2020. 
844 Nguyen, J.L. and Dockery, D.W., 2016. Daily indoor-to-outdoor temperature and humidity 845 relationships: a sample across seasons and diverse climatic regions. International Journal of 846 Biometeorology. 60, 221-229.

847

848 Otto, A.K., Reckien, D., Reyer, C.P.O., Marcus, R., Le Masson, V., Jones, L., Norton, A., 849 Serdeczny, O., 2017. Social vulnerability to climate change: a review of concepts and 850 evidence. Regional Environmental Change, 17, 1651-1662.

851

852 Rain D., Engstrom R., Ludlow, C., Antos, S., 2011. Accra Ghana: A City Vulnerable to 853 Flooding and Drought-Induced Migration. Case Study Prepared for Cities and Climate 854 Change: Global Report on Human Settlements 2011. Available from 855 http://www.unhabitat.org/grhs/2011.

856

857 Songsore, J., 2017. The complex interplay between everyday risks and disaster risks: the case 858 of the 2014 cholera pandemic and 2015 flood disaster in Accra, Ghana. International Journal of Disaster Risk Reduction, 26, 43-50.

860

UN Country Team Ghana. 2015. Ghana - Floods Situation Report. Accra: United Nations, 862 Ghana.

863

UNISDR 2009. Terminology in Disaster Risk Management. Available at: 865 https://www.unisdr.org/we/inform/terminology.

867 UNISDR 2015. Centre for Research on the Epidemiology of Disasters. The Human Cost of 868 Weather Related Disasters 2005-2015. 
869

870

871

872

873

874

875

876

877

878

879

880

881

882

883

884

885

886

887

888

889

890

891 Wright, C.Y., Street, R.A., Cele, N., Kunene, Z., Balakrishna, Y., Albers, P.N., Mathee, A. 892

$\underline{\text { NAL.pdf }}$ (date last accessed 10/06/19)

WHO. 2018. COP24 Special Report: Health and Climate Change. World Health Organization. https://apps.who.int/iris/bitstream/handle/10665/276405/9789241514972eng.pdf?ua $=1$

Wilby, R.L., 2007. A review of climate change impacts on the built environment. Built Environment Journal. 33, 31-45.

Wilby, R. L., Keenan, R., 2012. Adapting to flood risk under climate change. Progress in Physical Geography. 36(3), 348-378.

Wilunda, C., Scanagatta, C., Putoto, G., Montalbetti, F., Segafredo, G., Takahashi, R., Mizerero, S.A., Betrán, A.P., 2017. Barriers to utilisation of antenatal care services in South Sudan: a qualitative study in Rumbek North County. Reprod Health. 14(1), 65. doi: 10.1186/s12978-017-0327-0.

Woodward, A., Smith, K. R., Campbell-Lendrum, D., Chadee, D. D., Honda, Y., Liu, Q., ... \& Confalonieri, U. (2014). Climate change and health: on the latest IPCC report. The Lancet, 383(9924), 1185-1189. 2017. Indoor temperatures in patient waiting rooms in eight rural primary health care centers 
in Northern South Africa and the related potential risks to human health and wellbeing. Int. J.

894 Environ. Res. Public Health. 14, 43, doi:10.3390/ijerph14010043.

895

896 Yeboah, I.E.A., Codjoe, S.N.A., Maingi, J.K. 2013. Emerging urban system demographic 897 trends: informing Ghana's national urban policy and lessons for Sub-Saharan Africa. Africa 898 Today. 60(1), 98-124.

899

900 Zscheischler, J., Westra, S., Van Den Hurk, B.J., Seneviratne, S.I., Ward, P.J., Pitman, A., et 901 al. 2018. Future climate risk from compound events. Nature Climate Change, 8, 469-477. 


\section{Acknowledgements}

This project was funded by the British Academy under the Cities and Infrastructure Programme CI170211. The VEWEC team are extremely grateful to the Community Champions for facilitating the fieldwork and to all the participants who patiently answered our questions and repeatedly allowed us to enter their homes and workplaces to record the temperatures they experience. 


\section{Ethics Approval}

The study was approved by the Ethics Committee for the Humanities (ECH) of the University of Ghana with reference number ECH 109/17-18. 


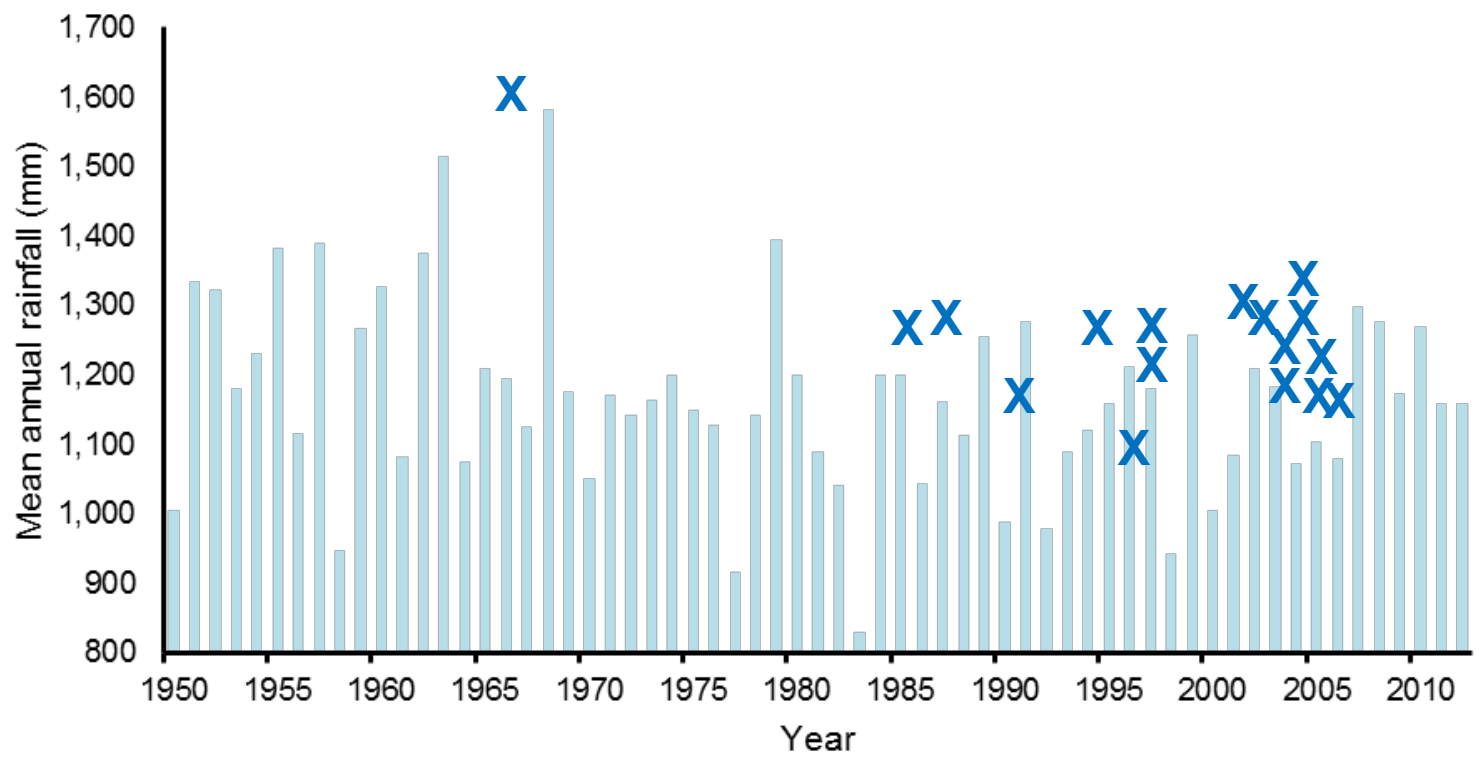

Figure 1. Extreme flood events relative to mean annual rainfall in Ghana from 1950 to 2012. Source: United Nations Office for Disaster Risk Reduction, 2009.

6

7

8

9

10

11

12

13

14

15

16 

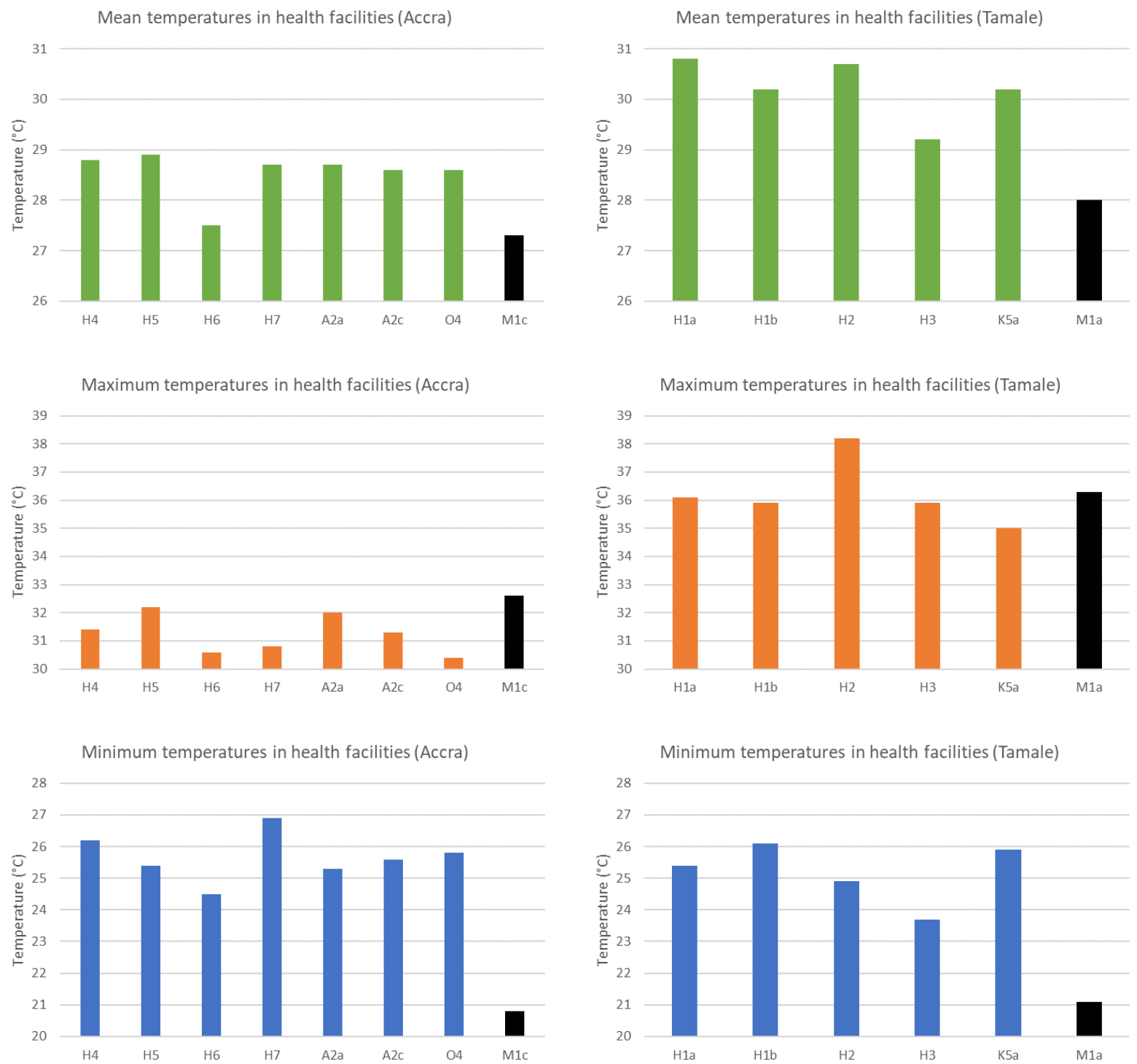

Figure 2. Mean, maximum and minimum indoor temperatures recorded at health facilities in Accra (left) and Tamale (right) during 22 May 2018 to 3 July 2018. H4, H5, H6, H7 and O4 are waiting rooms; A2a and $\mathrm{H} 1 \mathrm{~b}$ are children's wards; $\mathrm{A} 2 \mathrm{c}$ and $\mathrm{H} 2$ are outpatient departments; $\mathrm{H} 1 \mathrm{a}$ is a maternity ward; $\mathrm{H} 3$ is a labour ward; K5a is a health facility laboratory; M1c and M1a are the reference meteorological stations. 


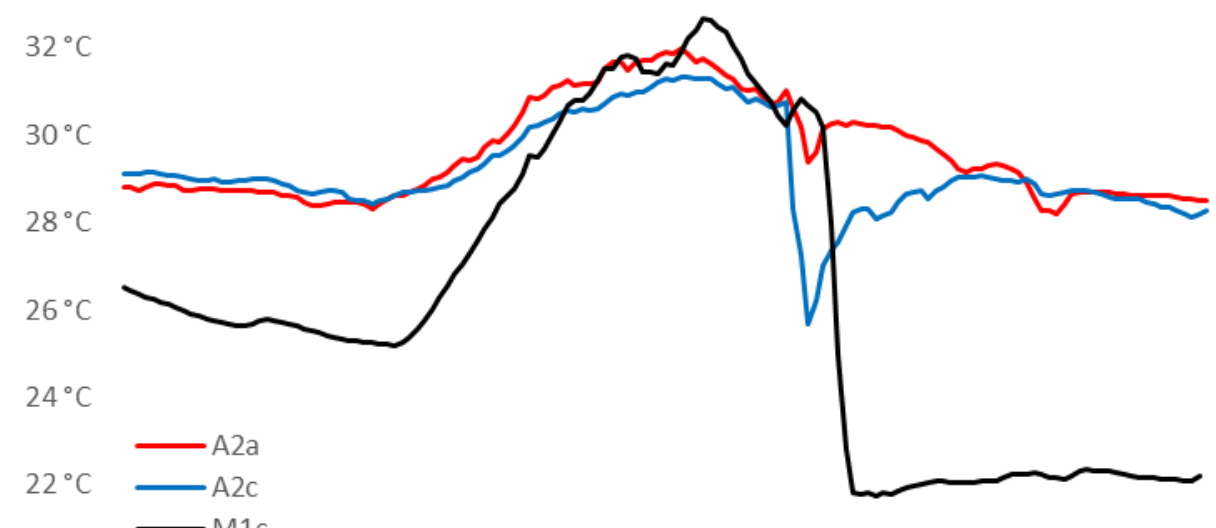

27

$20^{\circ} \mathrm{C}$

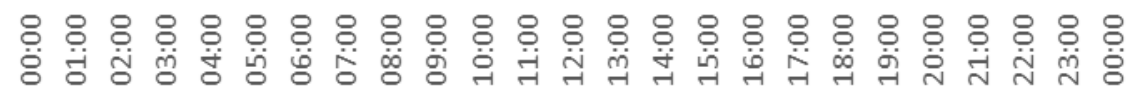

$33^{\circ} \mathrm{C}$
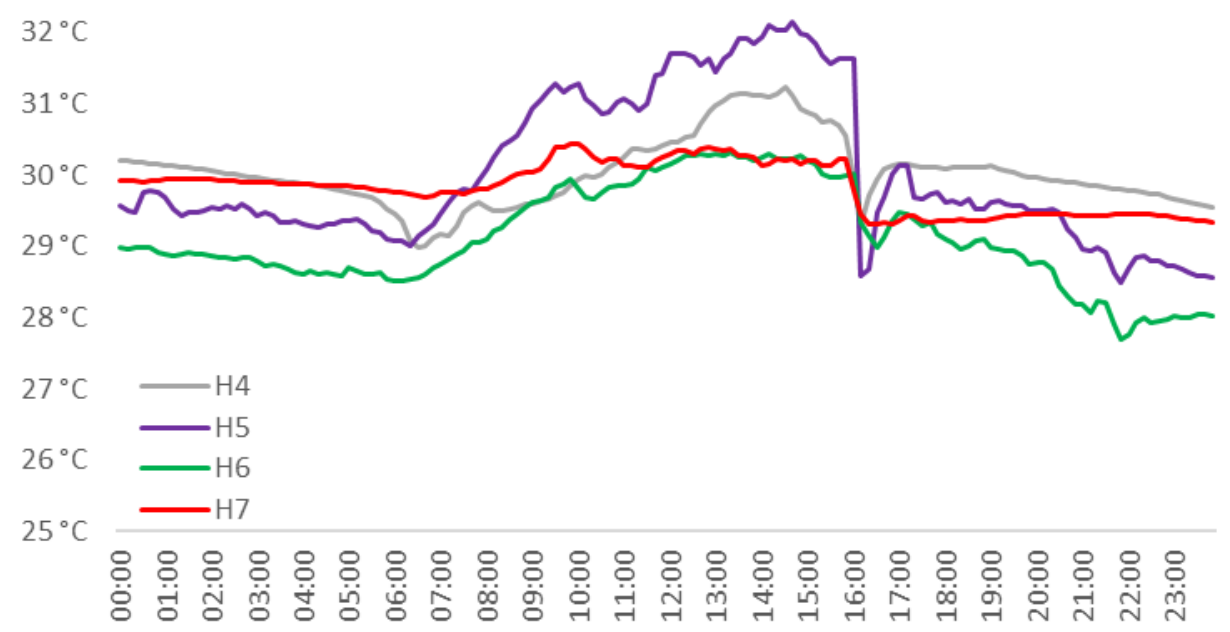

Figure 3. Comparison of 10-minute indoor temperatures for one of the hospitals (upper panel) and other health facilities (lower panel) in Accra on 6 June 2018. M1c is the reference meteorological station. 


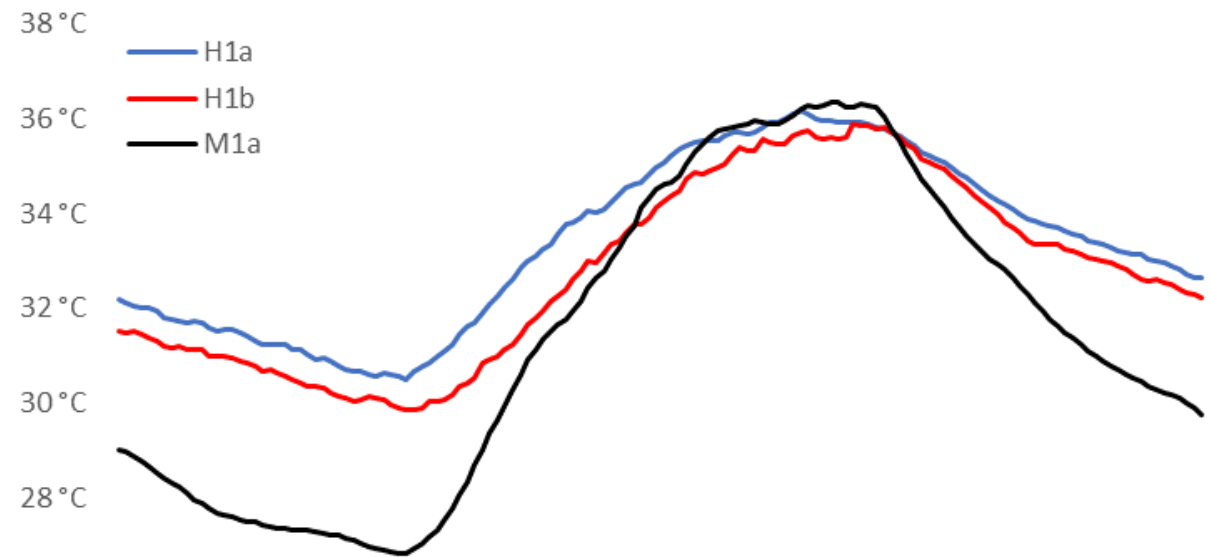

$39^{\circ} \mathrm{C}$

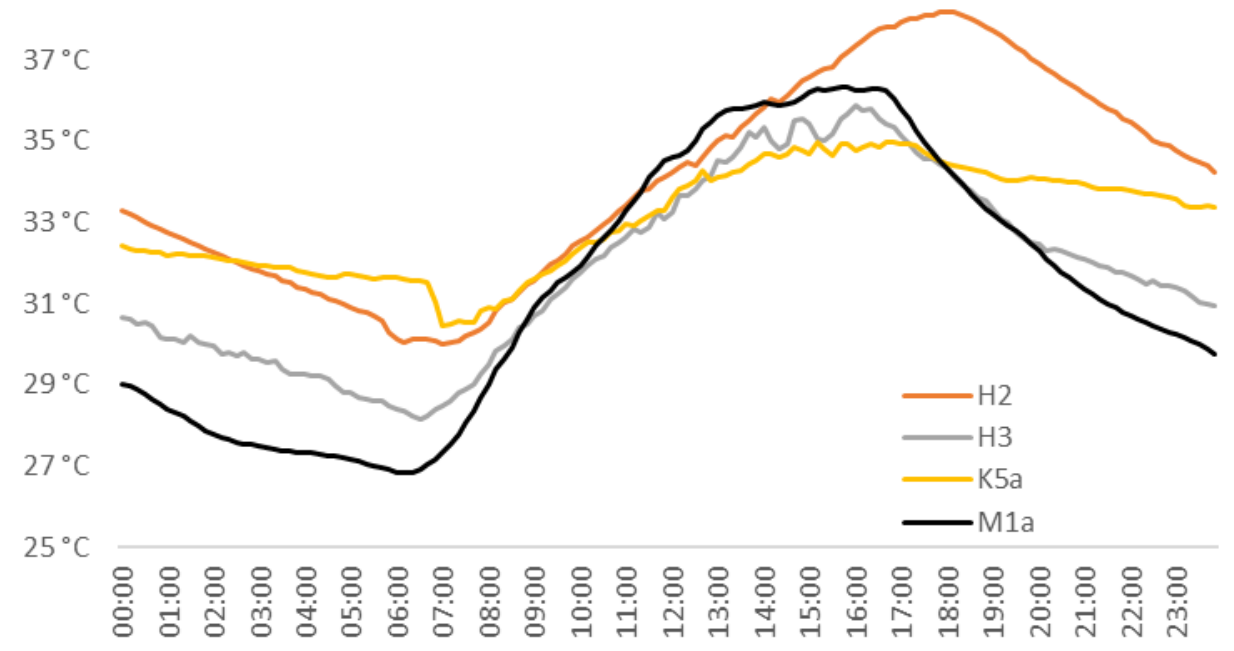

Figure 4. Comparison of 10-minute indoor temperatures for one of the hospitals (upper panel) and other health facilities (lower panel) in Tamale on 13 June 2018. M1a is the reference meteorological station. 

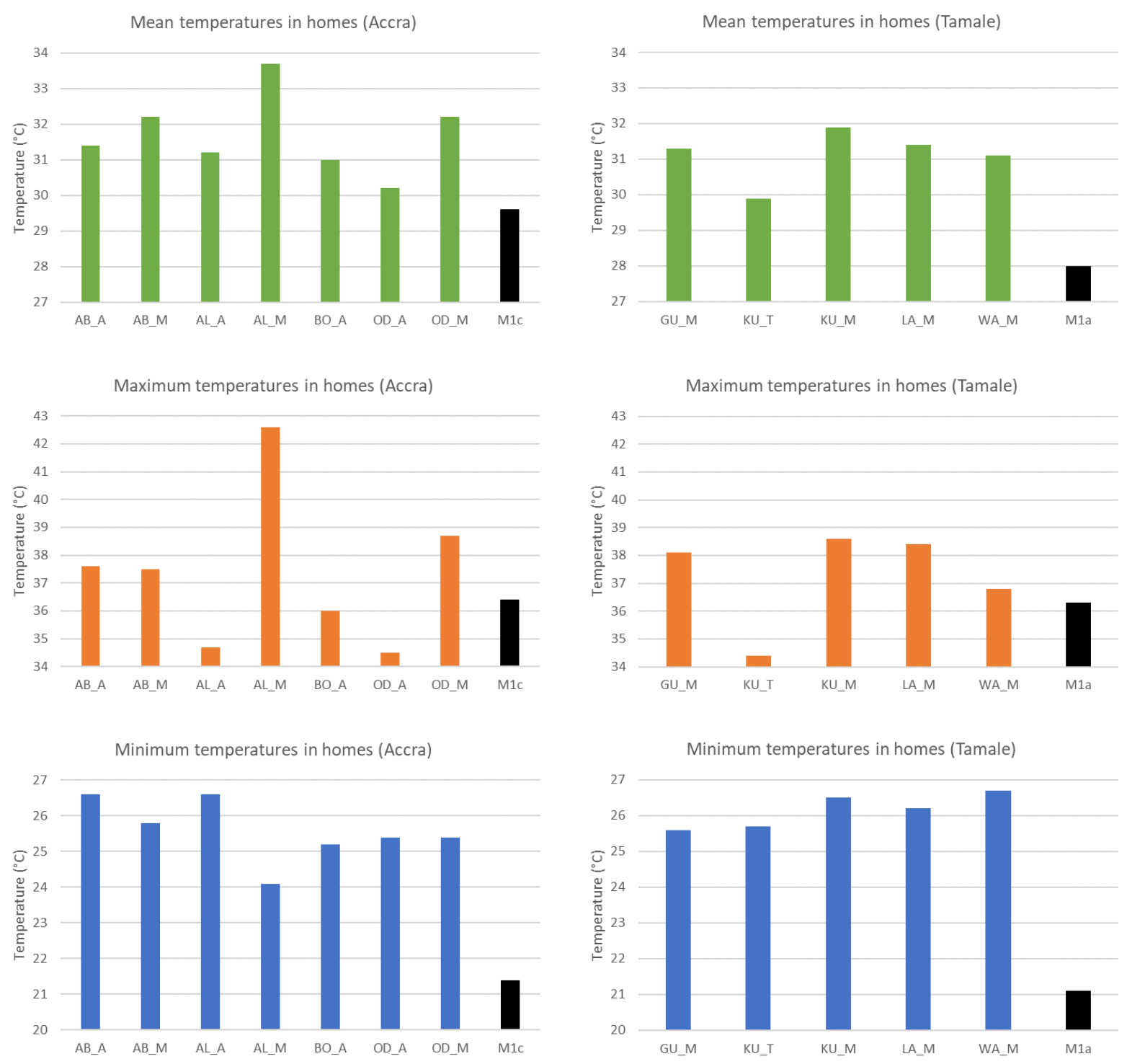

Figure 5. As in Figure 2 but for air temperatures in living rooms in sampled homes. The first two letters of the code denote the communities in Accra (Ablogbloshie, AB; Alajo, AL; Bortianor, BO; Odawna, OD) and Tamale (Gumani, GU; Kukuo, KU; Lamashegu, LA; Ward $\mathrm{K}, \mathrm{WA}$ ). Appended letters $\mathrm{A}, \mathrm{M}$ and $\mathrm{T}$ denote asbestos, metal and thatch roofed homes respectively. Values at reference meteorological stations (M1c and M1a) are given as before. 


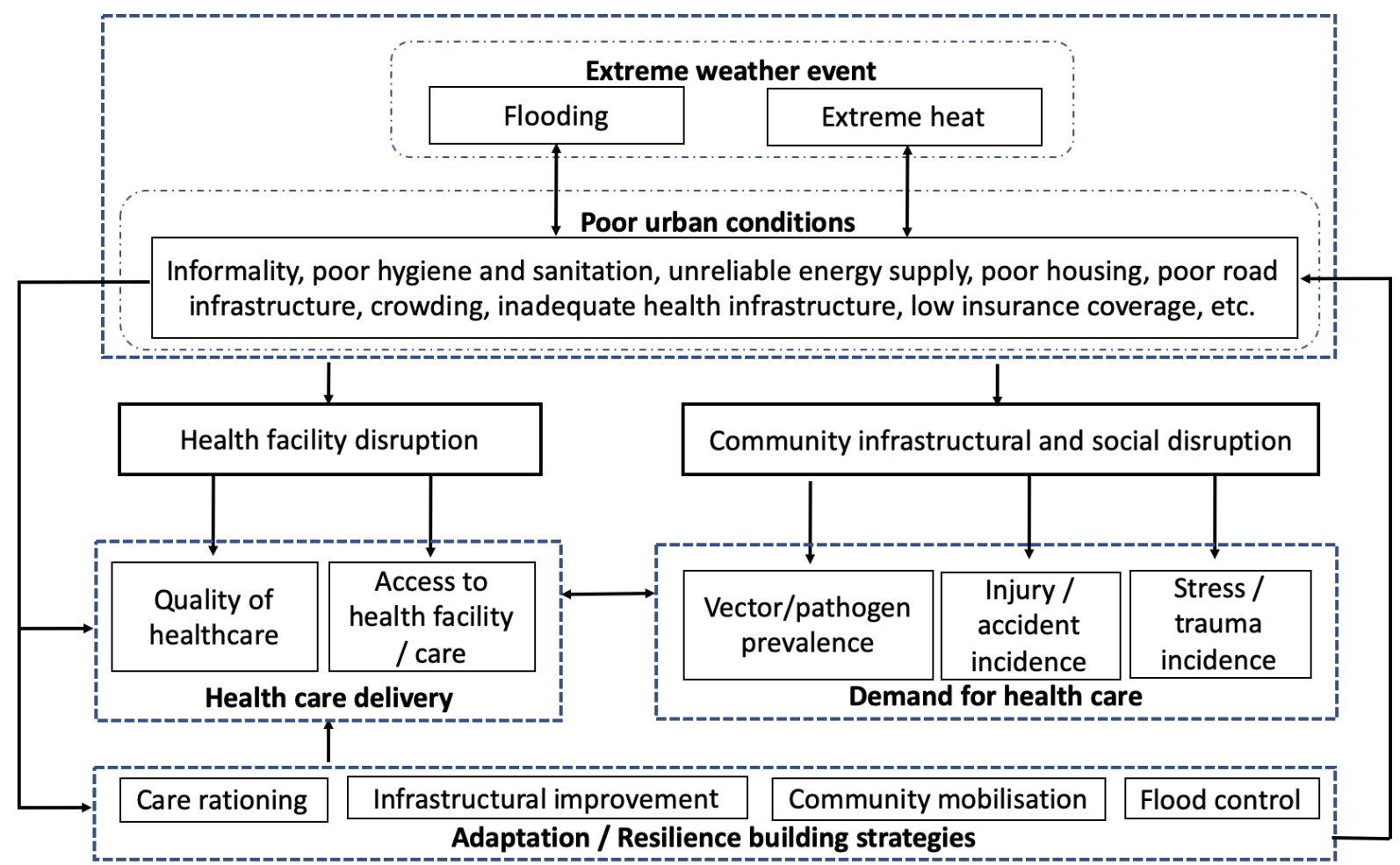

Figure 6: Links between extreme weather events and health in poor urban areas in Ghana. 
1 Table 1: Study settlements

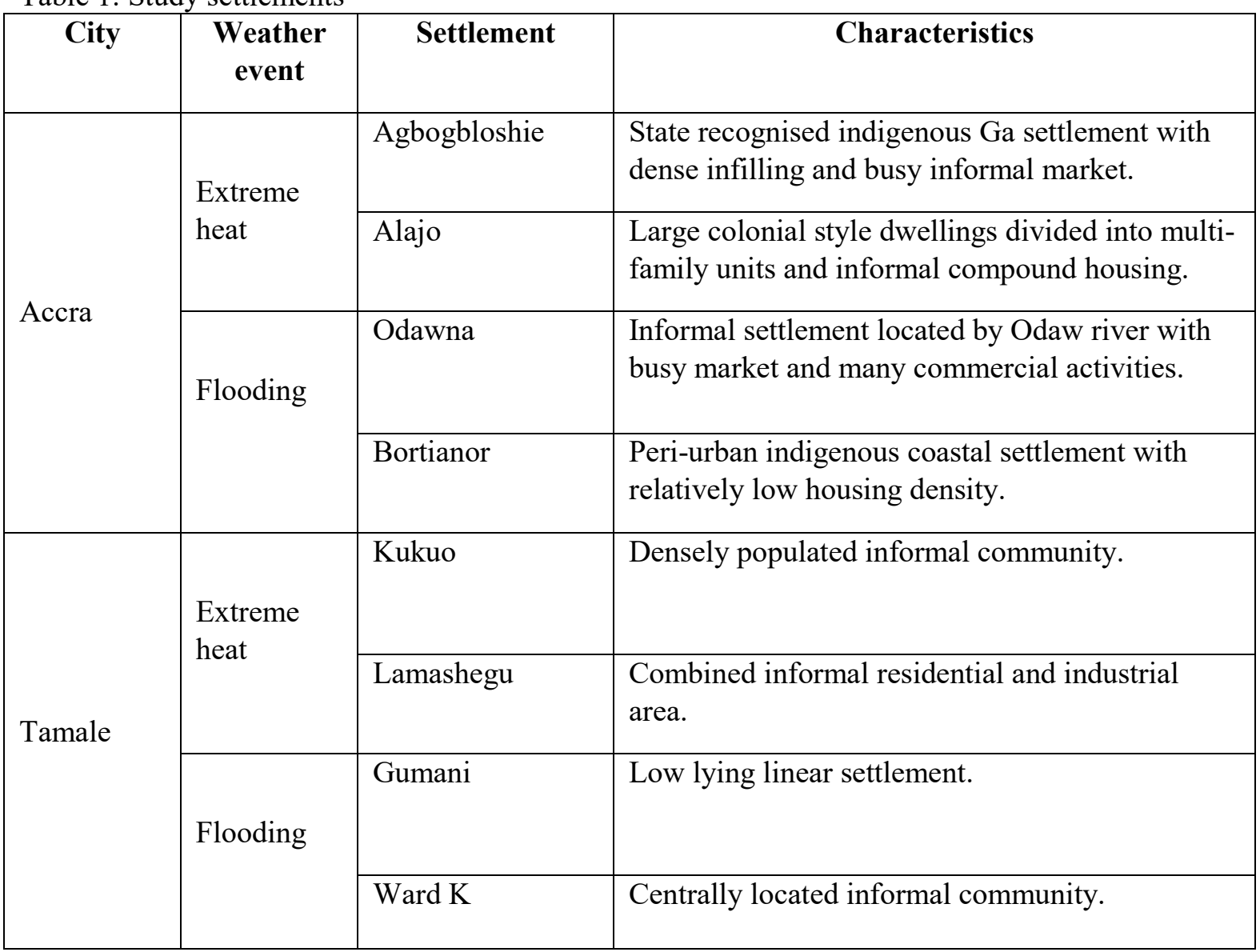

2 
Table 2. List of Participants in Key Informant Interviews

\begin{tabular}{|c|c|c|}
\hline Location & Personnel & Sex \\
\hline 1. Tamale & Medical Officer & Male \\
\hline 2. Tamale & Nurse-in-Charge & Female \\
\hline 3. Tamale & Nurse-in-Charge & Female \\
\hline 4. Tamale & Nurse-in-Charge & Female \\
\hline 5. Tamale & $\begin{array}{l}\text { Surgeon and Medical officer in } \\
\text { charge }\end{array}$ & Male/Male \\
\hline 6. Tamale & Medical Officer in Charge & Male \\
\hline 7. Tamale & Medical Officer in Charge & Male \\
\hline 8. Tamale & Pharmacist & Male \\
\hline 9. Tamale & Medical Officer & Male \\
\hline 10. Accra & Nurse & Female \\
\hline 11. Accra & $\begin{array}{l}\text { Health Facility Administrator and } \\
\text { nurse in charge (joint interview) }\end{array}$ & $\begin{array}{l}\text { Male/ } \\
\text { Female }\end{array}$ \\
\hline 12. Accra & Medical Officer & Male \\
\hline 13. Accra & Medical officer & Male \\
\hline 14. Accra & Medical Officer in Charge & Male \\
\hline 15. Accra & Medical Officer in Charge & Male \\
\hline 16. Accra & Pharmacist & Female \\
\hline
\end{tabular}

